\title{
Priapism following Phenothiazine therapy: A Case Report and Review of the Literature
}

\author{
Akhigbe K.O. and Uwadiae E.
}

\begin{abstract}
Chlorpromazine, a phenothiazine antipsychotic, is an old generation major tranquilizer that has remained relevant in the management of psychosis despite the advent of the newer atypical brands. Priapism, an uncommon urological condition may result from the alphaadrenergic blocking action of antipsychotics. A 46 years old man developed priapism in the course of treatment with chlorpromazine. He was only able to achieve penile detumescence (subsidence or diminution of swelling or erection of the penis) after surgical intervention. Medical practitioners must regard this as a reminder of the possible risk of priapism with the use of chlorpromazine which remains a main line drug in the treatment of agitated patients in developing, low income countries. Caution must therefore be exercised particularly when combining drugs with high affinity for alpha-adrenergic blockade and patients' vulnerability considered whenever possible.
\end{abstract}

\section{INTRODUCTION}

"Priapus" was the Greek god of procreation with an erect phallus as his symbol ${ }^{1}$. Priapism is a persistent unwanted erection that is not associated with sexual desire or sexual stimulation $^{2}$. It was first described by Tripe in 1845 in Lancet $^{3}$, and derives its name from "priapus". It is uncommon in men and rare in women and is an infrequent urologic emergency characterized by prolonged penile tumescence. It is usually associated with pain and tenderness

KEYWORDS: Priapism, phenothiazine

Department of Mental Health, University of Benin Teaching Hospital, Benin City, Nigeria.

Corresponding Author: Akhigbe K. O.

Koakhigbe@yahoo.com 08029501895. and requires urgent surgical intervention to forestall potentially problematic long term sequelae such as erectile dysfunction.

The aetiology of priapism is diverse. It is most often drug induced and the antidepressant drug Traxodone has been frequently implicated. Other psychoactive substances involved in the aetiology of priapism include marijuana, cocaine, ethanol, the atypical antipsychotics, (Risperidone, Olanzapine, Clozapine, Quetiapine, and Ziprasidone). Others are the older generation antipsychotics (e.g Haloperidol and Chlorpromazine) as well as antihypertensives such as prazosin, an alpha receptor antagonist. Other conditions that lead to priapism include Sickle Cell crises, leukemia, vascular abnormalities, and venous thrombosis from self-injection of narcotics, blocking the penis' venous drainage and thereby engorge it with blood. ${ }^{4}$ 
A 46-year-old celibate, never married Nigerian clergyman, was receiving treatment for Severe Depressive Episode. He had been physically aggressive on admission. He was placed on intramuscular Chlorpromazine 150mg stat followed by $200 \mathrm{mg}$ orally twice daily in addition to Amitriptyline $75 \mathrm{mg}$ orally daily. His refusal to accept oral medications made the use of parenteral medication inevitable. He responded favourably to treatment and was given "trial" discharge for one week. During this period, the patient sustained a penile erection without any erotic thought. The erection was painful. He disclosed at this point that the penile erection had actually been there for 2 weeks without remission. The urologist was invited to see him as an emergency. The Urologist observed a tumescent corpora carvenosa but a flaccid corpora spongiosun. Patient was given intracarvenosal adrenaline $0.5 \mathrm{ml}$ stat. There was only a marginal improvement. Two days later, intra carvenosal aspiration and irrigation with about $300 \mathrm{mls}$ of normal saline was done until detumescence was achieved. A dilute adrenaline solution was then used for irrigation before the needles were removed and dressings applied. The next day it was observed that there was a tumescent corpora carvenosa and a flaccid corpora spongiosun.

The patient was then taken to the theatre for irrigation under anaesthesia, followed by a bilateral spongiocarvenosal shunt during which over 20mls of dark blood was aspirated from the penis. The procedure was well tolerated and erection subsided. Subsequently, only occasional mild tumescence was observed. Chlorpromazine was discontinued and replaced with maintenance depot neuroleptic, flupenthixol decanoate $20 \mathrm{mg}$ monthly. The patient was monitored for 3 years on out patient basis and remained stable on the tricyclic antidepressant and depot neuroleptic.

\section{DISCUSSION}

Two types of priapism have been recognized: High flow (non ischaemic) and low flow (ischaemic). Ischaemic priapism is reported to be more common. It is associated with vascular stasis caused by a decrease in venous return. Tissue hypoxia and acidosis follow as well as pain and tenderness because of ischaemia of the tissues. Blood from the carvenous spaces in this type of priapism appears dark in colour. It requires urgent treatment to prevent penile tissue fibrosis. It would appear that the case reported in this paper is of the ischaemic type. High flow priapism is more often due to trauma though idiopathic causes and sickle cell disease have also been reported. The venous return is normal but there is an increased arterial supply thus aspirated blood has a high partial pressure of oxygen and appears bright red. This type of priapism is often painless, largely because it is not ischaemic. Surgical intervention may also prove useful but is not compulsory.

The treatment of priapism begins with forewarning the patient on its possibility particularly in patients with history of prolonged erections as this has been found to be present in as many as $50 \%$ of subsequent cases of priapism. Patients must also be counselled to report early for treatment once it is observed. Prompt treatment within 4 to 6 hours of onset of priapism has been shown to decrease morbidity as well as reduce the need for invasive procedures. It also reduces the risk of developing impotence. It is noteworthy that the patient reported in this paper did not seek consultation for more that two weeks.

Over the years, different antipsychotics have variously been reported in publications within and outside the African continent as being responsible for cases of priapism. Merkin (1977) reported an apparently healthy patient who had a single dose of chlorpromazine following a bout of hiccups ${ }^{1}$. He developed priapism for which conservative management was unsuccessful. Surgical intervention was done on the 15th day and the patient did well post-operatively. It however failed to caution on the need to discontinue conservative management when it's limitations are obvious and the patient not getting better. Expert urologic opinions hold that the longer the period of unrelieved priapism the more the chances of subsequent erectile dysfunction.

Kilciler et al (2003) reported priapism in a patient who had been on chlorpromazine for 3 years $^{2}$. Similarly Dorman and Schmidt (1976) reported four patients who presented over a 5 
years period $^{3}$. They were on Thioridazine, a phenothiazine antipsychotic. One of the patients had a trauma to the penis and this is another possible aetiologic factor in that case. Besides this patient, none had any underlying urologic or haematological disorders. They all had surgical shunt procedures to achieve penile detumescence. In addition, the authors also noted 6 other patients with priapism using a phenothiazine during the same period but for which the phenothiazine and the priapism were considered unrelated because other aetiologies were considered more likely. The possibility of a coincidence was highlighted. In a related report, Gomez et al (1991) commented on two cases of priapism in patients that were on phenothiazines ${ }^{5}$. Again, none of the patients had a history of any urologic or haematologic disorder. Both had emergency shunt procedures to achieve penile detumescence. However only one of the patients had an excellent result related to erectile function.

Various reports have implicated orally administered chlorpromazine in the aetiology of priapism just as chlorpromazine administered via other routes pose the same risk. Mutlu N, et al (1998) described two cases of priapism following orally administered chlorpromazine but in a rare development ${ }^{6}$. Jackson and Walker (1991) reported an unusual cause of priapism in a patient following self administered intra-urethral chlorpromazine ${ }^{7}$. The onset of priapism was 48 hours following application of chlorpromazine. It does appear that irrespective of the route of administration, chlorpromazine and indeed other phenothiazines remain potent aetiological factors in priapism. Similarly Van Hement, Meinhardt, Moehadjir and Kropman (1995) described a case of recurrent priapism as a side effect of Zuclopenthixol decanoate, a phenothiazine depot neuroleptic with a moderate alpha blocking effect ${ }^{8}$. The recurrent nature of the priapism in this case was a consequence of the long acting presentation of the Zuclopenthixol

\section{CONCLUSION}

The mechanism of erectile disturbances certainly needs more elucidation particularly concerning the role of psychoactive substances. The case reports highlighted in the literature review call for caution in the handling of phenothiazines. Every clinician must bear in mind the risk of priapism occasioned by the use of phenothiazines and the recurrent nature that long acting preparations can cause.

Chlorpromazine has remained invaluable as a major tranquilizer in the developing and low income countries because it is both affordable and readily available. Health care providers must not loose sight of the fact that it has a potential for priapism even when administered in the most unlikely and perhaps accidental route.

\section{References}

1. Merkin T. E., Priapism as a sequela of chlorpromazine therapy JACEP. 1977 Aug; 6(8): 367-8

2. Kilciler M, Bedir S, Sümer F, Dayanç M, Peker AF. Priapism in a patient receiving long-term chlorpromazine therapy. A case report. Urol Int. 2003;71(1):127-8.

3. Dorman B W, Schmilt J D. Association of Priapism in Phenothiazine therapy J Urol. 1976 Jul; 116 (1): 51-3

4. Kaufman D.M. Neurologic aspects of sexual function. In Kaufman DM Clinical Neurology for Psychiatrists, 6th ed. Philadelphia PA: Saunders, 2007: 362

5. Gómez Vegas A, Silmi Moyano A, Blázquez Izquierdo J, Corral Rosillo J, Delgado Martín JA, Gómez Ruiz JJ, Prieto Chaparro L, Salinas Casado J. Priapism secondary to phenothiazines Arch Esp Urol. 1991 Apr;44(3):287-9.

6. Mutlu N, Ozkurkcugil C, Culha M, Turkan S, Gökalp A. Priapism induced by chlorpromazine. Int J Clin Pract. 1999 Mar; 53(2): 152-3

7. Jackson S C, Walker J S Self administered intraurethral chlorpromazine: an unusual cause of priapism Am J Emer Med. 1991 Mar; 9(2):171-5

8. Van Hemert A M, Meinhardt W, Moehdjir D, Kropman R F. Recurrent priapism as a side effect of Zuclopenthixol deconoate Int Clin Psychopharmacol. 1985 Sept; 10(3): 199-200 